\title{
Differential contribution of HLA-DR, DQ, and TAP2 alleles to systemic lupus erythematosus susceptibility in Spanish patients: role of TAP2 ${ }^{\star} 01$ alleles in Ro autoantibody production
}

José M Martín-Villa, Jorge Martínez-Laso, Miguel A Moreno-Pelayo, Maria J Castro-Panete, Narcisa Martínez-Quiles, Miguel Alvarez, Maria D de Juan, Juan J Gómez-Reino, Antonio Arnaiz-Villena

Departments of Immunology

J M Martín-Villa

J Martínez-Laso

M A Moreno-Pelayo

M J Castro-Panete

N Martínez-Quiles

M Alvarez

A Arnaiz-Villena

and Rheumatology J J Gómez-Reino

Hospital Universitario "12 de Octubre", Universidad

Complutense, 28041

Madrid, Spain

Department of Immunology, Hospital Nta, Sra de Aránzazu, San Sebastián, Spain M D de Juan

Correspondence to: Dr A Arnaiz-Villena.

Accepted for publication 4 February 1998.

\begin{abstract}
Objective-To study the influence MHC class II and TAP2 alleles exert on systemic lupus erythematosus (SLE) susceptibility and on the clinical and serological manifestations of the disease, in a cohort of Spanish patients.
\end{abstract}

Methods-HLA-DR serological typing and HLA-DQA, DQB, and TAP2 DNA sequence specific oligotyping, were carried out in 85 unrelated Spanish SLE patients and 186 healthy controls. Autoantibodies detection was carried out by indirect immunofluorescence and counter immunoelectrophoresis.

Results-Total SLE group: the frequency of HLA-DR3 and HLA-DQA1 ${ }^{* 0501}$ is significantly increased in this group $\left(p_{c}<0.005, \delta=0.34\right.$ and $p_{c}<0.005, \delta=0.45$, respectively) although the highest $\delta$ value $(\delta=0.87)$ is obtained when the TAP2 ${ }^{\star} 01$ alleles are considered. No DQB allele shows significant deviation from the control group. Renal damage: it mainly occurs in HLA-DR3 patients $\left(p_{c}<0.0005\right.$ and $\delta=0.72)$. HLA-DQA1 ${ }^{\star} 0501 \quad\left(p_{c}<0.05\right.$, $\delta=0.57)$ and DQB1 ${ }^{\star 0201}\left(p_{c} N S, \delta=0.56\right)$ are weaker susceptibility factors. Ro+ (but not La) group: this autoantibody response is associated with $T A P 2{ }^{\star} 01$ alleles in homozygosity $(p<0.05, \delta=0.81)$. Ro/La+ group: it has a different genetic background as HLA-DQA1 ${ }^{\star} 0501 \quad(\delta=1)$ and HLA-DQB $1{ }^{\star} 0201(\delta=1)$ are the main susceptibility factors.

Conclusions-A differential association between HLA-DR, DQA1, and DQB1 alleles and SLE or its clinical and serological manifestations are found. Furthermore, the associations are different to the ones reported in other ethnic groups. Finally, TAP2 ${ }^{*} 01$ group of alleles are associated with the highest susceptibility to SLE (higher than HLA-DR3) and may influence Ro (but not La) autoantibodies production, whereas HLA-DQA1 ${ }^{\star 0501}$ and DQB1 ${ }^{\star} 0201$ mediates concomitant Ro and La production.

(Ann Rheum Dis 1998;57:214-219)

Systemic lupus erythematosus (SLE) is an autoimmune disorder with a large spectrum of clinical manifestations and a variety of immu- nological features. The disease is autoimmune in nature, and its precise aetiology remains poorly understood. ${ }^{1}$ Several studies have associated the polymorphic genes of the major histocompatibility complex (MHC) with susceptibility to SLE. ${ }^{2}$ Recent data suggest that the HLA system may exert its influence in the outcome and expression of the disease, and several HLA-DR and DQ markers or residues, or both, have been implicated in the appearance of specific autoantibodies. ${ }^{3}$ No single HLA locus has been involved in SLE susceptiblity and more than one HLA locus seem to be involved. To dissect the specific HLA susceptibility locus, it is necessary to study unusual haplotypes in which SLE associated alleles occur separated from their neighbours in individual families or in certain populations. The Spanish population displays differential associations of the disease with the HLA antigens, ${ }^{4}$ because the susceptibility allele DR3 is associated with the A30-B18-BfF1-C2C-C4A*3$\mathrm{C} 4 \mathrm{~B}^{\star} \mathrm{Q} 0$ haplotype, instead of the A1-B8-BfS$\mathrm{C} 2 \mathrm{C}-\mathrm{C} 4 \mathrm{~A}^{\star} \mathrm{Q} 0-\mathrm{C} 4 \mathrm{~B}^{\star} 1$ haplotype found in the North European populations. This fact makes the Spanish population suitable to carry out these studies.

TAP1 and TAP2 genes (TAP stands for transporter for antigen processing) are placed between HLA-DP and DQ ${ }^{5}$ and encode for proteins that deliver cytosolic peptides across the endoplasmic reticulum membranes (where TAP molecules are placed) to nascent intraluminal HLA class I molecules. ${ }^{6}$ Peptide binding is necessary for the conformational correctness and export to plasma membrane of HLA molecules. ${ }^{6}$ TAP2 genes, located close to DR-DQ, may confer SLE susceptibility, as TAP polymorphic proteins may be involved in the processing and presentation of putative autoantigens by HLA-class I proteins. TAP $2{ }^{\star} 01$ include a group of alleles with a stop codon at position 687 . $^{7}$

Because in the Spanish population DR3 susceptibility genes are placed in HLA chromosomes different from North European and other white populations, it is therefore a good and complementary model to pinpoint possible SLE susceptibility genes placed close to the $\mathrm{DR} / \mathrm{DQ}$ region. Thus, the purpose of this work was to study: (1) the association of SLE to HLA-DR, DQA, and DQB alleles in the Spanish population and (2) whether TAP2 alleles are SLE (or any of its clinical and serological 
manifestations) susceptibility factors and whether any of them increases the risk conferred by HLA class II alleles, as TAP2 has been found increased in other autoimmune disease (diabetes) in Spaniards. ${ }^{8}$

\begin{abstract}
Methods
PATIENTS

Eighty five unrelated SLE patients, diagnosed according to the American College of Rheumatology Criteria ${ }^{9}$ were studied. Among the patients, 25 with clinical evidence of renal disease had undergone kidney biopsy and classified according to the World Health Organisation criteria, slightly modified, ${ }^{10}$ as suffering from diffuse proliferative glomerulonephritis (DPGN). Patients lacking clinical evidence of renal disease were not biopsied. In a previous unpublished study of 20 SLE patients with no clinical evidence of renal disease, renal biopsy revealed only one with DPGN. Thus, patients with no evidence of renal disease were included in the non-DPGN group.

One hundred and eighty six unrelated adult healthy subjects of Spanish origin were used as controls. None had symptoms of SLE or other rheumatic disease and no ANA or ENA autoantibody was found in any of the healthy subjects tested.
\end{abstract}

HLA-DR AND DQ PHENOTYPING

HLA-DR antigens (HLA-DR1 through HLADR14, polymorphism encoded by the HLADRB1 gene) were determined by serology as previously described. ${ }^{11}$ HLA-DQA1 and HLADQB1 alleles recognised in the 11th Histocompatibility Workshop were detected by oligotyping as described elsewhere. ${ }^{11}$

The degree of HLA-DR polymorphism achieved by serology is adequate for the purpose of this work. However, given the limited HLA-DQ polymorphism obtained by serology, oligotyping techniques were used to study it, a decision also based on the fact that it has been recently suggested that there is a relevant role for HLA-DQ, rather than HLA-DR, in SLE susceptibility. ${ }^{12}$

SEQUENCE SPECIFIC OLIGOTYPING (SSO) ANALYSIS OF TAP2 VARIANTS.

Amplification products were obtained with the specific primers 5'-GGGGATCGCACAGT GCTGGTG and 5'-CTGGAATTCAGGA ACAGCTAT that contains the region between positions 1954 and 2204 of the TAP2 gene.

The presence of $\mathrm{TAP}^{\star}{ }^{\star} 01$, which comprises a group of alleles with a stop codon at residue 687 (Thr-665, Stop-687) and thus have a short cytoplasmic domain, and TAP2 ${ }^{\star} 0201$ (Ala665 , Gln-687) were tested by oligonucleotide typing using the oligoprobes 5'-AGGCT GCAGACAGTTCAG and 5'-AGGCTGC AGGCAGTTCAG to detect the variation in position 665 and 5'-ATTCCCGCCTGGT GCAGC and 5'-ATTCCCGCCTGGTTC AGC to detect the variation in position 687 , as previously described.
DETECTION OF AUTOANTIBODIES

Indirect immunofluorescence testing for antinuclear antibodies (ANA) was done in all serum samples using a human epithelioid cell line as substrate. Anti-ds-DNA autoantibodies were tested by indirect immunofluorescence using Crithidia lucilliae as substrate. The presence of precipitating autoantibodies to SSA/Ro, SSB/La, Sm, and RNP was ascertained by double immunodiffusion and counter immunoelectrophoresis in agarose by using prototype reference serum with known antiRo, anti-La, anti-Sm, and anti-RNP activity. ${ }^{13}$

\section{STATISTICS}

The distribution of the frequencies of each HLA-DR, DQA, DQB, and TAP2 allele in SLE patients (in the total SLE group and in the different subgroups) and control subjects was compared calculating $\chi^{2}$ test (with Yates's correction) or Fisher test when appropriate, $\delta$ (aetiological fraction value), relative risk (RR), and their corresponding level of significance corrected by the number of alleles tested when appropriate $\left(\mathrm{p}_{\mathrm{c}}\right)$, as previously described. ${ }^{14}$ All these calculations were made using two Fortran IV programs. ${ }^{15}$

Aetiological fraction value $(\delta)$ indicates the extent to which a given allele contributes to the appearance of the disease at the population level (compared with other factors that conspire to produce the disease).$^{16} \delta$ Value has advantages over $R R$ values when the association is caused by linkage disequilibrium between a genetic marker and the true "diseased" genetic marker, both markers being very close at the genomic level. As the true susceptibility marker is unknown, this type of analysis will assign higher $\delta$ values to the genetic markers placed closer to the true susceptibility markers or loci, irrespective of any difference in the frequency of the two antigen alleles. The $\delta$ value may be used to quantify the strength of association of the HLA markers as an almost absolute measure of the strongest linkage disequilibrium. It is calculated as $\delta=d-p / 1-p$, where $d$ denotes the frequency of a given allele in the disease population, and $\mathrm{p}$ in the control healthy population. Its value ranges between 0 and 1.0 denoting no contribution at all to the appearance of the disease, and 1 absolute contribution.

The mode of inheritance (recessive or dominant) of $\mathrm{TAP} 2{ }^{\star} 01$ group of alleles or TAP $2 \star 0201$, susceptibility or resistance alleles, respectively, was tested by the Thomson and Bodmer method. ${ }^{17}$

\section{Results}

SEROLOGICAL HLA-DR FREQUENCIES

Table 1 shows the relevant associations between HLA class II antigens and SLE or its clinical or serological manifestations. These results confirm and complete previous data obtained by our group. ${ }^{18}$

HLA-DR3 antigen

It shows a significant increase in the SLE group $\left(52 \% v 27 \%\right.$ in controls, $\left.\mathrm{p}_{\mathrm{c}}<0.005\right)$ and in the DPGN+ (79\%, $\left.\mathrm{p}_{\mathrm{c}}<0.0005\right), \mathrm{Ro}^{+}(65 \%$, 
Table 1 Relevant serological HLA class II alleles associations in SLE patients and its clinical and serological manifestations (\%)

\begin{tabular}{llllllll}
\hline & $\begin{array}{l}S L E \\
(n=81)\end{array}$ & $\begin{array}{l}\text { DPGN+ } \\
(n=24)\end{array}$ & $\begin{array}{l}\text { DPGN- } \\
(n=37)\end{array}$ & $\begin{array}{l}\text { Ro } \\
(n=20)\end{array}$ & $\begin{array}{l}\text { Ro/La } \\
(n=8)\end{array}$ & $\begin{array}{l}\text { Ro alone } \\
(n=12)\end{array}$ & $\begin{array}{l}\text { Control } \\
(n=186)\end{array}$ \\
\hline DR1 & 10 & 8 & $5 \S$ & 10 & 0 & 17 & 19 \\
DR3 & $52 \dagger$ & $79 \ddagger$ & 43 & $65^{\star}$ & $88^{\star}$ & 50 & 27 \\
DR4 & 15 & 8 & 14 & 5 & 13 & 0 & 22 \\
DR7 & $19 \star$ & 17 & $22 \S$ & 25 & 25 & 25 & 38 \\
DR11 & 25 & 17 & $35 \S$ & 30 & 13 & 42 & 17 \\
DR12 & 2 & 0 & 3 & 5 & $13 \S$ & 0 & 0 \\
DR13 & $35^{\star}$ & 33 & $43^{\star \star}$ & 35 & $50 \$$ & 25 & 17 \\
\hline
\end{tabular}

${ }^{\star} \mathrm{p}_{\mathrm{c}}<0.05,{ }^{\star \star} \mathrm{p}_{\mathrm{c}}<0.01, \dagger \mathrm{p}_{\mathrm{c}}<0.005, \neq \mathrm{p}_{\mathrm{c}}<0.0005 . \mathrm{p}_{\mathrm{c}}$ Values are corrected by the number of alleles tested. \$Denotes significances lost after correction.

Table 2 Relevant HLA-DQA1 and DQB1 antigens associations in SLE patients and its clinical and serological manifestations (\%)

\begin{tabular}{|c|c|c|c|c|c|c|c|}
\hline & $\begin{array}{l}S L E \\
(n=81)\end{array}$ & $\begin{array}{l}\text { DPGN+ } \\
(n=25)\end{array}$ & $\begin{array}{l}D P G N- \\
(n=37)\end{array}$ & $\begin{array}{l}R o \\
(n=19)\end{array}$ & $\begin{array}{l}R o / L a \\
(n=7)\end{array}$ & $\begin{array}{l}\text { Ro alone } \\
(n=12)\end{array}$ & $\begin{array}{l}\text { Control } \\
(n=176)\end{array}$ \\
\hline $\mathrm{DQA}^{\star}{ }^{\star} 0101$ & 19 & 24 & $13 \ddagger$ & 21 & 14 & 25 & 31 \\
\hline DQA $1 * 0201$ & $23 \ddagger$ & 24 & 27 & 37 & 14 & 50 & 38 \\
\hline DQA $1{ }^{\star} 0501$ & $\begin{array}{l}69 \dagger \\
(n=82)\end{array}$ & $\begin{array}{l}76^{\star} \\
(n=25)\end{array}$ & $\begin{array}{l}70^{\star} \\
(\mathrm{n}=37)\end{array}$ & $\begin{array}{l}74 \\
(n=21)\end{array}$ & $\begin{array}{l}100^{\star} \\
(\mathrm{n}=9)\end{array}$ & $\begin{array}{l}58 \\
(\mathrm{n}=12)\end{array}$ & $\begin{array}{l}44 \\
(n=176)\end{array}$ \\
\hline $\mathrm{DQB} 1{ }^{\star} 0501$ & 13 & 12 & $8^{\star}$ & 19 & $0 \ddagger$ & 33 & 30 \\
\hline $\mathrm{DQB} 1{ }^{\star} 0604$ & 11 & $16 \ddagger$ & 8 & 14 & 22 & 8 & 3 \\
\hline DQB $1{ }^{\star} 0201$ & 62 & $80 \ddagger$ & 62 & $86 \ddagger$ & $100 \ddagger$ & 75 & 54 \\
\hline $\mathrm{DQB} 1{ }^{\star} 0301$ & 32 & 16 & $46 \neq$ & 29 & 22 & 33 & 23 \\
\hline
\end{tabular}

${ }^{\star} \mathrm{p}_{\mathrm{c}}<0.05,+\mathrm{p}_{\mathrm{c}}<0.005, \mathrm{p}_{\mathrm{c}}$ Values are corrected by the number of alleles tested. $¥$ Denotes significan ces lost after correction.

Table 3 Relevant TAP2 antigens associations in SLE patients and its clinical and serological manifestations (\%)

\begin{tabular}{llllllll}
\hline & $\begin{array}{l}S L E \\
(n=85)\end{array}$ & $\begin{array}{l}\text { DPGN+ } \\
(n=25)\end{array}$ & $\begin{array}{l}\text { DPGN- } \\
(n=40)\end{array}$ & $\begin{array}{l}\text { Ro } \\
(n=21)\end{array}$ & $\begin{array}{l}\text { Ro/La } \\
(n=9)\end{array}$ & $\begin{array}{l}\text { Ro alone } \\
(n=12)\end{array}$ & $\begin{array}{l}\text { Control } \\
(n=155)\end{array}$ \\
\hline TAP2 ${ }^{\star} 01$ & $99^{\star}$ & 96 & 98 & 100 & 100 & 100 & 90 \\
0201 & 32 & 28 & 30 & $14^{\star \star}$ & 22 & $8^{\star}$ & 44 \\
$01 / 01$ & 68 & 72 & 70 & $86^{\star \star}$ & 78 & $92^{\star}$ & 56 \\
$01 / 0201$ & 31 & 24 & 28 & $14^{\star}$ & 22 & 8 & 34 \\
$0201 / 0201$ & $1^{\star}$ & 4 & 2 & 0 & 0 & 0 & 10 \\
\hline
\end{tabular}

${ }^{\star} \mathrm{p}<0.05,{ }^{\star \star} \mathrm{p}<0.01$.

$\left.\mathrm{p}_{\mathrm{c}}<0.05\right)$, and $\mathrm{Ro} / \mathrm{La}+\left(88 \%, \mathrm{p}_{\mathrm{c}}<0.05\right)$ groups. In the Spanish population all HLA-DR3 antigens are always HLA-DRB $1^{\star} 0301$, associated with HLA-DQA $1{ }^{\star} 0501$ and DQB1*0201; thus no DR3 subgroups can be made, based on its association with DQ alleles. ${ }^{19}$

\section{HLA-DR7 antigen}

It is decreased in the total SLE group (19\% v $\left.38 \%, \mathrm{p}_{\mathrm{c}}<0.05\right)$, in keeping with our previous data, where a decrease of the extended haplotype B44-DR7 was reported. ${ }^{18}$

\section{$H L A-D R 13$ antigen}

A significant increase in HLA-DR13, not previously reported, is found in the total SLE group (35\% v 17\% in controls, $\left.\mathrm{p}_{\mathrm{c}}<0.05\right)$ and in the DPGN- $\left(43 \%, \mathrm{p}_{\mathrm{c}}<0.01\right)$.

HLA-DQ OLIGOTYPING

Table 2 shows the most relevant associations of the HLA-DQA and DQB alleles, as assessed by PCR-SSO.

\section{$H L A-D Q A^{\star} 0501$ allele}

It is found increased in the total SLE group $\left(69 \% v 44 \%\right.$ in controls, $\left.\mathrm{p}_{\mathrm{c}}<0.005\right), \mathrm{DPGN}+$ $\left(76 \%, \mathrm{p}_{\mathrm{c}}<0.05\right)$, DPGN- $\left(70 \%, \mathrm{p}_{\mathrm{c}}<0.05\right)$, and $\mathrm{Ro} / \mathrm{La}+\left(100 \%, \mathrm{p}_{\mathrm{c}}<0.05\right)$. This allele is found in HLA-DR3, DR1 1 and in some DR13 bearing haplotypes. As HLA-DR3 and DR13 have been found increased in several groups of patients (see above), the susceptibility mediated by DQ might be secondary to that mediated by DR; however, when the $\delta$ value of each allele is calculated (see below), DQA $1{ }^{\star} 0501$, rather than any DR antigen, shows a primary association to SLE or SLE related symptoms, except in the DPGH+ group.

\section{$H L A-D Q A 1^{\star} 0201$ allele}

It is decreased, though not significantly, in the total SLE group. This finding may reflect the low HLA-DR7 frequency found in this (see above) and past studies. ${ }^{18}$

As for DQB1, several alleles show deviations from the control group, although most of the significances are lost after multiplication by the number of alleles tested (see table 2).

\section{$H L A-D Q B 1^{\star} 0501$ allele}

It shows however, a significant reduction in the DPGN $\left(8 \% \quad v 30 \%\right.$ in controls, $\left.\mathrm{p}_{\mathrm{c}}<0.05\right)$ patients. This DQ allele is found mainly in HLA-DR1 and DR10 bearing haplotypes, and none of them is found at a significant lower when compared with the healthy group.

\section{$H L A-D Q B 1{ }^{\star} 0201$ allele}

This allele, present in HLA-DR3 haplotypes, is found increased though not significantly $\left(p_{c}>0.05\right)$, when compared with the control group, although HLA-DR3 shows a very high frequency in the total SLE group and several subgroups (DPGN+, Ro+, and Ro/La+). This can be explained by the high proportion of HLA-DR7 (in linkage with HLA$\mathrm{DQB} 1^{\star} 0201$ ) found in healthy individuals (38\%, see table 1$)$.

\section{TAP2 ALLELES (TABLE 3)}

Susceptibility associated to TAP2 201 (group of shorter protein alleles, stop codon at residue $687^{8}$ ) TAP $2{ }^{\star} 01$ is found in $90 \%$ of Spanish controls; this frequency is similar to the one found by Ronningen and coworkers in Scandinavian populations. ${ }^{20}$ However, $99 \%$ patients carry the allele, showing a significant deviation from the control group $(\mathrm{p}<0.05$, table 3$)$. Insulin dependent diabetes mellitus in Spanish patients yields similar percentages. ${ }^{8}$ Moreover, this increase was not caused by the existence of linkage disequilibrium to any of the class I or class II alleles conferring susceptibility to SLE in our population: no linkage disequilibrium was found between TAP $2{ }^{\star} 01$ and any of the classically defined class I and class II alleles. ${ }^{8}$ The $\delta$ value obtained (see below) shows that TAP2 ${ }^{\star} 01$ allele is the strongest SLE susceptibility marker in Spanish patients (see table 4).

Protection associated to TAP2*0201 allele (group of longer protein alleles, glutamine at residue $687^{8}$ ) TAP2 ${ }^{\star} 0201$ allele is found in $44 \%$ of Spanish people; this frequency is similar to that in Scandinavian populations. ${ }^{20}$ Its frequency is diminished in ANA+ $(28 \%, \mathrm{p}<0.05$ data not shown), Ro+ (14\%, p<0.01), and Ro+ alone $(8 \%, p<0.05)$ patients. Moreover, homozygous $\mathrm{TAP}^{\star}{ }^{\star} 0201 / 0201$ subjects are found in $1 \%$ SLE patients and in $10 \%$ of healthy controls 
Table $4 \Delta$ value of HLA markers in SLE patients and the clinical and serological manifestations

\begin{tabular}{|c|c|c|c|c|c|c|c|}
\hline$S L E$ & $\begin{array}{l}\text { TAP2 } 2^{\star} 01 \\
\delta=0.87\end{array}$ & $\begin{array}{l}D Q A 1 \\
\delta=0.45\end{array}$ & $\begin{array}{l}\text { DR3 } \\
\delta=0.34\end{array}$ & $\begin{array}{l}D R 13 \\
\delta=0.21\end{array}$ & & & \\
\hline DPGN+ & $\begin{array}{l}\text { DR3 } \\
\delta=0.72\end{array}$ & $\begin{array}{l}\text { DQA } 1{ }^{\star} 0501 \\
\delta=0.57\end{array}$ & $\begin{array}{l}\mathrm{DQB} 1{ }^{\star} 0201 \\
\delta=0.56\end{array}$ & $\begin{array}{l}\mathrm{DQB} 1{ }^{\star} 0604 \\
\delta=0.13\end{array}$ & & & \\
\hline DPGN- & $\begin{array}{l}\text { DQA } 1{ }^{\star} 0501 \\
\delta=0.47\end{array}$ & $\begin{array}{l}\text { DR13 } \\
\delta=0.32\end{array}$ & $\begin{array}{l}\mathrm{DQB} 1{ }^{\star} 0301 \\
\delta=0.30\end{array}$ & $\begin{array}{l}\text { DR11 } \\
\delta=0.22\end{array}$ & $\begin{array}{l}\text { DR3 } \\
\delta=0.22\end{array}$ & & \\
\hline Ro & $\begin{array}{l}\text { DR3+ } \\
\text { TAP2*01/01 } \\
\delta=0.86\end{array}$ & $\begin{array}{l}\text { DQA1 }{ }^{\star} 0501+ \\
\text { TAP2 }{ }^{\star} 01 / 01 \\
\delta=083\end{array}$ & $\begin{array}{l}\mathrm{DQB} 1^{\star} 0201+ \\
\mathrm{TAP} 2^{\star} 01 / 01\end{array}$ & $\mathrm{DQB} 1{ }^{\star} 0201$ & $\mathrm{TAP} 2 \star 01 / 01$ & DQA $1{ }^{\star} 0501$ & DR3 \\
\hline $\mathrm{Ro} / \mathrm{La}$ & $\begin{array}{l}\delta=0.86 \\
\text { DQA } 1^{\star} 0501 \\
\delta=1\end{array}$ & $\begin{array}{l}\delta=0.83 \\
\mathrm{DQB} 1{ }^{\star} 0201 \\
\delta=1\end{array}$ & $\begin{array}{l}\delta=0.80 \\
\text { DR3 } \\
\delta=0.82\end{array}$ & $\begin{array}{l}\delta=0.68 \\
\text { DR13 } \\
\delta=0.40\end{array}$ & $\delta=0.67$ & $\delta=0.53$ & $\delta=0.52$ \\
\hline Ro alone & $\begin{array}{l}\text { TAP2 } 2^{\star} 01 / 01+ \\
\text { DR11 } \\
\delta=1\end{array}$ & $\begin{array}{l}\text { TAP2 }{ }^{\star} 01 / 01 \\
\delta=0.81\end{array}$ & $\begin{array}{l}\text { DR11 } \\
\delta=0.30\end{array}$ & & & & \\
\hline
\end{tabular}

$(p<0.05)$. Thus $\mathrm{TAP}^{\star}{ }^{\star} 0201$ seems to exert opposite effects to what has been found with $\mathrm{TAP} 2{ }^{\star} 01$. This diminished frequency is not caused by linkage disequilibrium with protective class I or class II factors in our population (results not shown).

It is uncertain whether TAP $2^{\star} 0201$ protection only reflects $\mathrm{TAP} 2{ }^{\star} 01$ susceptibility, because the mathematical processing of our data has taken both "alleles" as true alleles of a diallelic system.

\section{Inheritance of TAP2 alleles in SLE patients}

The mode of inheritance of TAP2 201 alleles was tested in our SLE population using the Thomson and Bodmer method. ${ }^{17}$ The data obtained yield no deviation either from the recessive or the dominant model in any of the two alleles (recessive: TAP2 ${ }^{\star} 01 / 0170 \%$, TAP2 ${ }^{\star} 01 / 020127 \%$, TAP2 ${ }^{\star} 0201 / 02013 \%$, p>0.05; dominant: TAP2 ${ }^{\star} 01 / 01 \quad 67 \%$, TAP2 ${ }^{\star} 01 / 020132 \%$, TAP2 ${ }^{\star} 0201 / 0201 \quad 1 \%$ $\mathrm{p}>0.05)$, suggesting an intermediate model of inheritance of the disease.

As expected, the mode of inheritance of TAP2*0201 allele does not fit to either the recessive or dominant model of inheritance. (Recessive: TAP2 ${ }^{\star} 0201 / 0201 \quad 3 \%$, TAP2 ${ }^{\star} 0201 / 01 \quad 27 \%$, TAP2 ${ }^{\star} 01 / 01 \quad 70 \%$, p>0.05; dominant: TAP2 ${ }^{\star} 0201 / 02012 \%$, TAP2 ${ }^{\star} 0201 / 01 \quad 29 \%$; $\quad$ TAP2 ${ }^{\star} 01 / 01 \quad 69 \%$, $\mathrm{p}>0.05)$.

\section{Discussion}

The genetics underlying SLE remain far from clear, but recent data suggest that the HLA system may influence the outcome and expression of the disease. In this study a group of Spanish SLE patients were categorised according to the presence of renal damage and the autoantibodies detected. Their HLA-DR, DQ and TAP2 phenotype or genotype was also studied.

\section{TAP2 ALLELE FREQUENCIES}

When the different subsets of patients were analysed (table 3 ), $\mathrm{TAP}^{\star}{ }^{\star} 01$ alleles were significantly increased in ANA+ patients (98\% $v 90 \%$ in controls, $\mathrm{p}<0.05$, data not shown). Remarkably, a high frequency of TAP $2 \star 01 / 01$ homozygous people was observed in ANA+ patients $(72 \%$ v $56 \%$ in controls, $\mathrm{p}<0.05$, data not shown), Ro+ $(86 \%, \mathrm{p}<0.01)$, and Ro+ alone patients $(92 \%, \mathrm{p}<0.05)$. Moreover, and based on the $\delta$ values obtained when several
HLA allele combinations are considered, it appears as if the TAP2 ${ }^{\star} 01$ allele exerts an additional susceptibility effect (see below).

A previous report by Davies et $a l^{11}$ found no association between TAP2 alleles and SLE and only a weak association between the TAP2C allele (variant included in the TAP $2{ }^{\star} 01$ group of alleles) and susceptibility to produce circulating anti-Ro (but not anti-La) autoantibodies. This discrepancy may be explained assuming that the genetic markers underlying the clinical and serological manifestations of SLE, differ depending on the population studied.

$\triangle$ VALUE COMPARISONS IN THE TOTAL SLE GROUP AND SUBGROUPS

Table 4 shows the $\delta$ values obtained with different HLA markers, in the SLE total group and its clinical and serological subgroups.

\section{SLE group}

The highest susceptibility to SLE is present in TAP $2{ }^{\star} 01$ positive subjects because it displays the highest $\delta$ value $(\delta=0.87)$. If non-DR3 subjects were considered (controls $n=114$, patients $\mathrm{n}=39$ ), the susceptible TAP2 ${ }^{\star} 01$ alleles (controls $89 \%$, patients $97 \%, p_{c}>0.05$, results not shown) still remain as such, although significance is not reached, probably because of the low number of patients tested. These results suggest that $\mathrm{TAP} 2^{\star} 01$ allele may exert an additional and independent susceptibility to suffer from SLE, in HLA-DR3 people.

HLA-DQA ${ }^{\star} 0501$ is, according to its $\delta$ value $(\delta=0.45)$, the second SLE susceptibility allele. This allele is present in HLA-DR3 and in some DR13 bearing haplotypes and both alleles are found significantly increased in SLE Spanish patients (see table 1); this therefore explains the $\delta$ value obtained. In fact HLADR 3 and DR13 show a lower $\delta$ value $(\delta=0.34$ and $\delta=0.21$, respectively).

\section{Renal damage (DPGN+)}

It is associated to HLA-DR3 $(79 \% v 27 \%$ in controls $\mathrm{p}_{\mathrm{c}}<0.0005$ and $\delta=0.72$, see tables 1 and 4), whereas HLA-DQA and DQB factors do not play such an important part in this group of patients. This finding confirms our previously published data. ${ }^{18}$

If DPGN+ SLE patients are compared with DPGN- SLE patients, a HLA-DR3 increase and a DQB $1^{\star} 0301$ decrease is observed, though significance is lost upon correction in both instances $\left(79 \% v 43 \%, \mathrm{p}_{\mathrm{c}}=0.065\right.$ and 
$16 \% v 46 \%, \mathrm{p}_{\mathrm{c}}=0.187$, respectively. Data not shown).

Ro+ group

The appearance of Ro autoantibodies, whether alone or concomitantly with $\mathrm{La}$, is associated to different genetic markers in Spanish patients.

Ninety two per cent of the patients presenting Ro (without La) autoantibodies are TAP2 ${ }^{\star} 01 / 01$ homozygous $v 56 \%$ of controls $\left(\mathrm{p}_{\mathrm{c}}<0.05, \delta=0.81\right.$, see tables 3 and 4$)$. HLADR11 is increased in the patients group when compared with the control group, although significance is lost when corrected by the number of comparisons made $\left(\mathrm{p}_{\mathrm{c}}>0.05\right.$, $\delta=0.3)$. When both genetic markers are considered together (DR1 1 and TAP2 ${ }^{\star} 01$ homozygosity) a $\delta=1$ is obtained ( $\mathrm{p}$ value after correction $\mathrm{p}_{\mathrm{c}}>0.05$, results not shown). If non-DR11 subjects were considered (controls $n=72$, Ro+ alone patients $n=6$ ) susceptibility associated to TAP2 ${ }^{\star} 01 / 01$ homozygosity still remains as such, although significance is not reached $\left(55 \%\right.$ v $86 \%, \mathrm{p}_{\mathrm{c}}>0.05, \delta=0.68$, results not shown) probably because of the low number of patients tested. These results suggest that $\mathrm{TAP} 2{ }^{\star} 01$ mediated susceptibility acts independently of the DR locus. Finally, the inheritance of the TAP2 alleles in this group of patients shows a clear recessive model (recessive: expected frequency $\mathrm{TAP} 2{ }^{\star} 01 / 0192 \%$, TAP2 ${ }^{\star} 01 / 02018 \%$, TAP2 ${ }^{\star} 0201 / 02010 \%$, p $>0.05$; dominant: TAP2 $2^{\star} 01 / 01 \quad 30 \%$, TAP2 ${ }^{\star} 01 / 020167 \%$, TAP2 ${ }^{\star} 0201 / 02013 \%$, $\mathrm{p}<0.00005)$. This model of inheritance differs from the one found in the total SLE group (see results).

However, when the simultaneous production of Ro and La autoantibodies is considered, different genetic susceptibility markers are found. As table 2 shows, HLA-DQA ${ }^{\star} 0501$ is present in $100 \%$ of patients $v 44 \%$ of controls $\left(\mathrm{p}_{\mathrm{c}}<0.05\right)$ and HLA-DQB $1^{\star} 0201$ in $100 \%$ patients $v 54 \%$ controls $\left(\mathrm{p}_{\mathrm{c}}>0.05\right)$. Both alleles display the highest $\delta$ value $(\delta=1$, table 4$)$ and meet the postulated hypothesis that associates susceptibility to produce Ro autoantibodies to the presence of a residue of glutamine at position 34 of the $\mathrm{DQ} \alpha$ chain and leucine at position 26 of the DQ $\beta$ chain. ${ }^{3}$ The DQA $1{ }^{\star} 0501 / \mathrm{DQB} 1{ }^{\star} 0201$ heterodimer, either in cis or trans, has been implicated in the susceptibility to other autoimmune diseases, such as dermatitis herpetiformis in Spaniards ${ }^{22}$ and coeliac disease in white patients. ${ }^{23}$ Interestingly, all but one of our $\mathrm{Ro} / \mathrm{La}+$ patients are HLA-DR3, bearing this DQ heterodimer in cis. The remaining one is HLA-DR7/DR11 thus bearing it in trans.

TAP2 mediated SLE susceptibility has already been studied in other ethnic groups. ${ }^{21}$ TAP2C frequency (variant included in the $\mathrm{TAP} 2{ }^{\star} 01$ group of alleles) was increased in patients with circulating anti-Ro (but not antiLa) antibodies, although this significance was lost upon correction. However, Davies et $a l^{11}$ failed to analyse whether homozygosity would increase the susceptibility risk. On the other hand, the concomitant production of Ro and La autoantibodies is mainly mediated by
HLA-DQA $1{ }^{\star} 0501$ and $\mathrm{DQB} 1{ }^{\star} 0201$ alleles and no TAP2 allele appears implicated (see table 4). Thus, the genetic background leading to the production of Ro autoantibodies alone is different from that leading to concomitant $\mathrm{Ro} / \mathrm{La}$ autoantibodies. A similar conclusion was already reached by Reichlin and coworkers. In his work, ${ }^{24}$ SLE patients with Ro autoantibody production alone or with concomitant Ro and La production were HLA phenotyped, and it was concluded that genetic factors (HLA) were responsible for the serological differences between these two groups, and it was suggested that there was an independent control of antibodies to Ro on the one hand and joint regulation in the production of antibodies to Ro and $\mathrm{La}$ on the other.

The finding of an association between the $\mathrm{TAP}^{\star}{ }^{\star} 01$ allele and Ro (but not La) autoantibodies, may be explained by the fact that this is the only autoantigen of those tested in this study that shows a clear cytoplasmic distribution. ${ }^{25}$ Thus, there is a hypothetical possibility (among others) that the shorter group of alleles would have a functional difference (enhancing) in transporting a putative Ro autoimmunogenic peptide and ease its presentation to CD8 aggressive T lymphocytes. When present in homozygosity, the patients would be more prone to producing Ro autoantibodies.

The implication of TAP genes has been studied in rheumatic diseases other than SLE. ${ }^{26}$ These studies disclosed little evidence for TAP alleles in disease susceptibility, although a minor effect on disease phenotype has been proposed. However, TAP alleles showed linkage disequilibrium with HLA-DR4 in the populations in which these studies were carried out, and it was concluded that the associations found were secondary to the linkage disequilibrium. This is not the case in our population, and thus the conclusions reached in this study are firmly substantiated.

Further challenges to the study of TAP alleles and disease susceptibility come from the work by Obs et al. ${ }^{27}$ They concluded that TAP polymorphism had no influence on peptide selection and that its contribution to disease progression and autoimmunity was not very likely. It can, however, be argued that: (1) as already suggested by the authors, ${ }^{27}$ subtle differences among TAP alleles were noted in the transport of a given peptide and as the reasons for these minor differences are unclear, it cannot be excluded that they can have functional consequences (that is, autoinmunity), (2) the fact that no differences were found in the peptides assayed in the experiment $^{27}$ does not necessarily parallel physiological conditions after antigenic challenge with pathogens, where a wide array of peptides may be generated and variations at positions other than the shown in that experiment ${ }^{27}$ may have a dramatic effect in peptide transport, (3) the methodology used to detect peptide transport may be far less efficient than $\mathrm{T}$ cell activation and thus, differences in the transport, roughly detected in the experimental model used may be readily detected by $\mathrm{T}$ lymphocytes and have functional 
consequences, and (4) because TAP2 molecules interact with HLA class I molecules acting as chaperones, in the delivery process of foreign peptides to HLA molecules, differences either in the TAP or HLA class I alleles, may also affect the travel of foreign peptides to the cell surface.

If comparisons between SLE patients with or without Ro autoantibodies (concomitantly or not with La autoantibodies) are carried out, several deviations are found although none reach significance upon correction.

The fact that comparisons between SLE patients with clinical manifestations or autoantibodies and SLE patients without them, do not reach significance upon correction (whereas it is maintained when comparisons are carried out with the healthy group) can be explained by the low number of patients present in some of the groups.

Our results show that the appearance of autoantibodies in Spanish SLE patients, is associated to different HLA alleles to those found in other populations. It should not be considered remarkable because it must be noted that the frequency with which these autoantibodies appear depends on the ethnic group studied. The pattern of production of autoantibodies in our population is closer to that of Mexican patients than to, for instance, black American patients. This differential production pattern has been stated in international collaborative studies. ${ }^{28}$ Thus, the appearance of autoantibodies is a genetic trait that differs depending on the population studied. This would explain the contradictory results found in the literature concerning the linkage between HLA alleles and autoantibodies in SLE patients.

From this study, it can be deduced that there is a differential HLA association to SLE or to its clinical and serological manifestations in Spanish SLE patients, supporting the notion that the HLA genes mediate susceptibility to the manifestations of the disease, rather than to SLE itself. ${ }^{29}$

In summary, our results show that: (1) there is a differential association of HLA markers to SLE and its clinical or serological manifestations, as different genes underlie their appearance; (2) these associations differ to what has been reported in other ethnic groups; and (3) TAP2 ${ }^{\star} 01$ allele is associated to SLE susceptibility and, more prominently, in the production of Ro (without La) autoantibodies.

This work was supported by Fondo de Investigaciones Sanitarias. Ministerio de Sanidad, Spain. JMM-V and JM-L contributed equally to this study.

1 Arnett FC, Reveille JD. Genetics of Systemic lupus erythematosus. Rheum Dis Clin North Am 1992;16:86592.

2 Reichlin M, Harley JB, Lockshin MD. Serologic studies of monozygotic twins with systemic lupus erythematosus. Arthritis Rheum 1992;35:457-64.

3 Reveille JD, MacLead MJ, Whittington K, Arnett FC. Specific aminoacid residues in the second hypervariable region of HLA-DQA1 and DQB1 chain genes promote the Ro (SS-A)/La (SS-B) autoantibody responses. J Immunol (SS-A)/La (SS-B)
$1991 ; 146: 3871-6$.
4 De Juan MD, Martin-Villa JM, Gómez-Reino JJ, Vicario JL, Corell A, Martínez-Laso J, et al. Differential contribution of C4 and HLA-DQ genes to systemic lupus erythematosus. Hum Genet 1993;91:579-84.

5 Campbell RD, Trowsdale J. Map of the human MHC. Immunol Today 1993;14:349-52.

6 Parham P. Transporters of delight. Nature 1990;348:674-5.

7 Powis SH, Mackridge I, Kelly A, Glynne R, Gileadi S, Beck $\mathrm{S}$, et al. Polymorphism in a second transporter gene located within the class II region of the human major histocompatibility complex. Proc Natl Acad Sci USA 1992;89:1463-7.

8 Martínez-Laso J, Martín-Villa JM, Alvarez M, MartínezQuiles N, Lledó G, Arnaiz-Villena A. Susceptibility to insulin-dependent diabetes mellitus and short cytoplasmic ATPulin-dependent diabetes mellitus and short cytoplasmic 184-8.

9 Tan EM, Cohen AS, Fries JF, Marsh AT, McShane DJ, Rothfield NF, et al. The 1982 revised criteria for the diagnosis of systemic lupus erythematosus. Arthritis Rheum 1982;25:1271-7.

10 Pirani CL, Pollak VE. Systemic lupus erythematosus glomerulonephritis. In: Rose N, ed. Immunological mediated renal diseases: criteria for diagnosis. New York: Marcel Dekker, 1978:283-95.

11 Arnaiz-Villena A, Benmamar D, Alvarez M, Díaz-Campos N, Varela P, Gómez-Casado E, et al. HLA allele and haplotype frequencies in Algerians: relatedness to Spaniards and type frequencies in Algerians: relatedness to
Basques. Hum Immunol 1995;43:259-68.

12 Schur PH. Genetics of systemic lupus erythematosus. Lupus 1995;4:425-37.

13 Greenwald CA, Peebles CL, Nakamura RM. Laboratory test for antinuclear antibody in rheumatic diseases. Lab Med 1978;9:19-30.

14 Vicario JL, Martínez-Laso, Corell A, Martín-Villa JM, Morales P, Lledó G, et al. Comparison between HLA-DR and DQ DNA sequences and classic serological markers as Type I (insulin-dependent) diabetes mellitus predictive markers in the Spanish population. Diabetología 1992;35: 475-81.

15 Vicario JL, Martínez-Laso J, Corell A, Regueiro JR, ArnaizVillena A. Both HLA class II and class III restriction fragment length polymorphism factors linked to rheumatoid ment length polymorphism factors linked to rheumatoid juvenile

16 Thomson G, Motro V, Selvin S. Statistical aspects of measuring the strength of associations between HLA antigens and diseases. Tissue Antigens 1983;21:320-8.

17 Thomson G, Bodmer W. The genetic analysis of HLA and disease. In: Dausset J, Svejgaard A, eds. HLA and disease. Copenhagen: Munksgaard, 1977:84-93.

18 Gómez-Reino JJ, Martínez-Laso J, Vicario JL, Paz-Artal E, Aragón A, Martín-Villa JM, et al. Immunogenetics of systemic lupus erythematosus in Spanish patients: differensystemic lupus erythematosus in Spanish patients: differ
tial HLA-markers. Immunobiology 1991;182:465-71.

19 Martínez-Laso J, De Juan D, Martínez-Quiles N, GómezCasado E, Cuadrado E, Arnaiz-Villena A. The contribution of the HLA-A,-B,-C and -DR,-DQ DNA typing to the study of the origins of Spaniards and Basques. Tissue Antigens 1995;45:237-45.

20 Ronningen KS, Undlien DE, Ploski R, Maauni N, Konrad RJ, Jensen E, et al. Linkage disequilibrium between TAP2 variants and HLA class II alleles; no primary association between TAP2 variants and insulin-dependent diabetes mellitus. J Immunol 1993;23:1050-6.

21 Davies EJ, Donn RP, Hillarby MC, Greenan DM, Ollier WER. Polymorphism of the TAP2 transporter gene in systemic lupus erythematosus. Ann Rheum Dis 1994;53: temic $61-3$.

22 Balas-Pérez A, García-Sánchez F, Martínez-Laso J, GómezReino F, Vicario JL, Martínez MJ, et al. Inmunogenética de la dermatitis herpetiforme. Un modelo de asociación absoluta al sistema HLA. Inmunología 1992;11:115-19.

23 Lundin KEA, Scott H, Hansen T, Paulsen G, Halstensen B, Fousa $S$, et al. Gliadin specific, HLA-DQ $\left(\alpha 1^{\star} 0501, \beta^{\star} 0201\right)$ restricted, $T$ cells isolated from the small intestinal mucosa of coeliac disease patients. J Exp Med 1993;178:187-92.

24 Reichlin M, Harley JB. Antibodies to Ro (SSA) and the heterogeneity of systemic lupus erythematosus. J Rheumatol 1987;14:112-17.

25 García-Lerma JC, Sequí-Navarro J, Vela-Olmo C. Carterísticas moleculares de los autoantígenos SSA/Ro, $\mathrm{SSB} / \mathrm{La}$ y Sm/RNP (Sm y U1RNP). Inmunología 1994;13: 85-101.

26 Coakley G, Lanchbury JS. MHC-encoded TAP genes in rheumatic diseases. Br J Rheumatol 1996;35:501-5.

27 Obst R, Armandola EA, Nijenhuis M, Momburg F, Hammerling GJ. TAP polymorphism does not influence transport of peptide variants in mice and humans. Eur J Immunol 1995;25:2170-6.

28 Bias WB, Hochberg MC, McLean RH, Machan C. Systemic lupus erythematosus joint report. In: Tsuji K,
Aizawa M, Sasazuki T, eds. HLA 1991. Proceedings of the eleventh International Histocompatibility Workshop and Conference (Volume 1). Oxford: Oxford Science Publications, 1992:740-5.

29 Arnett FC. Genetics aspects of human lupus. Clin Immunol Immunopathol 1992;63:4-6. 